\title{
Gambaran Karakteristik dan Kepuasan Peserta BPJS Kesehatan dalam Pemanfaatan Pelayanan Kesehatan di FKTP Kota Malang
}

\author{
Febri Endra Budi Setyawan \\ Fakultas Kedokteran, Universitas Muhammadiyah Malang,febri@umm.ac.id
}

\begin{abstract}
ABSTRAK
Adanya aturan tentang kenaikan iuran Badan Penyelenggara Jaminan Sosial (BPJS) Kesehatan baru-baru ini memengaruhi terjadinya sejumlah 800 ribu peserta yang turun kelas. Saat ini, tingkat kepuasan peserta BPJS Kesehatan terhadap pelayanan kesehatan di Fasilitas Kesehatan Tingkat Pertama (FKTP) masih berada di bawah target. Kepuasan peserta BPJS Kesehatan saat mendapatkan pelayanan kesehatan di FKTP akan memberikan pengaruh yang kuat terhadap loyalitas peserta dan kualitas pelayanan kesehatan. Penelitian ini bertujuan untuk mengetahui gambaran karakteristik dan kepuasan peserta BPJS Kesehatan dalam pemanfaatan pelayanan kesehatan di FKTP Kota Malang. Studi ini merupakan penelitian deskriptif dengan menggunakan pendekatan survei observasional deskriptif untuk menggambarkan karakteristik dan kepuasan peserta BPJS Kesehatan. Penelitian ini melibatkan sejumlah 49 peserta BPJS yang ada di FKTP Kota Malang yaitu pada FKTP Klinik Pratama dan FKTP Puskesmas. Penentuan sampel diperoleh dengan systematic random sampling. Hasil penelitian menunjukkan bahwa pada kedua jenis FKTP, $100 \%$ peserta BPJS menyatakan tidak pernah pindah kepesertaan dari FKTP. Seluruh peserta Penerima Bantuan Iuran (PBI) memeriksakan kesehatannya di FKTP puskesmas, sedangkan pada FKTP Klinik Pratama, sebagian besar pesertanya (75\%) adalah Pekerja Penerima Upah (PPU). Tingkat kepuasan peserta BPJS di FKTP Klinik Pratama lebih banyak didominasi oleh aspek biologis (84,85\%), sedangkan aspek psikis lebih banyak dirasakan oleh peserta di FKTP Puskesmas. Kesimpulan penelitian ini menunjukkan bahwa peserta PBI lebih banyak memeriksakan kesehatan di FKTP Puskesmas dan kepuasan pada aspek biologis lebih dirasakan di FKTP Klinik Pratama. Kepuasan peserta BPJS Kesehatan di FKTP Klinik Pratama dan FKTP Puskesmas perlu ditingkatkan melalui pendekatan holistik komprehensif dengan upaya promotif, preventif, kuratif dan rehabilitatif.
\end{abstract}

Kata kunci: karakteristik, kepuasan, peserta BPJS, FKTP

\begin{abstract}
The rules regarding the increase in Social Insurance Administration Organization (BPJS) Health fees recently affected the occurrence of 800 thousand BPJS Health participants who dropped out of class. The level of satisfaction of BPJS Health participants utilizing health services at the First Level Health Facilities (FKTP) was still below the target. The satisfaction of the participants of the BPJS of Health when getting health services in FKTP will have a strong influence on their loyalty and the quality of health services in general. This study conducted to describe the characteristics and satisfaction of BPJS Health participants in the utilization of health services in FKTP Malang. This study wass a descriptive study an observational survey approach to describe the characteristics and satisfaction of BPJS Health participants. This study involved 49 BPJS participants in FKTP Malang at the Primary Care Clinic and Community Health Center by using systematic random sampling. Results: The results showed that in both types of FKTP groups, 100\% of participants stated that they preserved their chosen health services. All participants of the Subsidy Aid Recipient (PBI) checked their health at the Community Health Center, while at the primary care clinic, the majority of participants (75\%) were Wage Recipient Workers (PPU). The level of satisfaction of BPJS participants in primary care clinic was more dominated by biological aspects (84.85\%), while psychological aspects were more felt by participants in Community Health Center. In conclusion, The conclusion of this study shows that PBI participants checks their health more at Community Health Center and they felt more satisfy on biological aspects at Primary Care Clinic. BPJS Health participants' satisfaction in both FKTP groups needs to be improved through a comprehensive holistic approach with promotive, preventive, curative and rehabilitative efforts.
\end{abstract}

Keywords: characteristics, satisfaction, BPJS participants, First-Level Health Facilities

*Korespondensi Author: Febri Endra Budi Setyawan, Fakultas Kedokteran, Universitas Muihammadiyah Malang, febri@umm.ac.id, Jl. Bendungan Sutami 188A, Malang, Jawa Timur, Telp.: +62-341-551149 


\section{PENDAHULUAN}

Paradigma baru pelayanan kesehatan di Indonesia pada saat ini telah difokuskan pada pelayanan kesehatan yang bersifat pencegahan penyakit dan promosi kesehatan dengan memperhatikan mutu dan jaminan pembiayaan kesehatan. Setiap warga negara diharuskan memiliki program jaminan sosial, dimana salah satunya adalah Badan Penyelanggara Jaminan Sosial (BPJS) Kesehatan yang telah beroperasi sejak tahun 2014. ${ }^{1,2}$ Jaminan Kesehatan Nasional (JKN) ini telah diatur di dalam Peraturan Presiden Nomor 82 Tahun 2018 dimana setiap peserta mendapatkan pelayanan kebutuhan dasar kesehatan setelah membayar iuran sesuai dengan kategori kelompok kepesertaan BPJS. ${ }^{3}$

Saat ini terdapat dua kategori kepesertaan BPJS, yaitu Penerima Bantuan Iuran (PBI) dan Bukan PBI. Sedangkan kelompok bukan PBI selanjutnya dikategorikan menjadi Pekerja Penerima Upah (PPU), Pekerja Bukan Penerima Upah (PBPU) dan Bukan Pekerja (BP). Semua peserta BPJS akan memperoleh hak dan pelayanan kesehatan yang setara sesuai dengan besaran premi atau iuran yang telah dibayarkan. ${ }^{3}$

Peserta BPJS mendapatkan dua manfaat pelayanan kesehatan berupa manfaat medis dan non medis di Fasilitas Kesehatan Tingkat Pertama (FKTP) maupun Fasilitas Kesehatan Tingkat Lanjutan (FKRTL). Manfaat medis yang dirasakan oleh seluruh kelompok peserta BJPS dalam hal ini setara, artinya tidak dipengaruhi oleh jumlah premi yang telah dibayar. Namun, semakin besar biaya premi yang dikeluarkan, maka peserta BPJS akan mendapatkan manfaat non medis (fasilitas kesehatan) yang lebih besar berupa jenis akomodasi layanan rawat inap. Jika peserta BPJS ingin melakukan peningkatan akomodasi layanan rawat inap yang lebih tinggi dari haknya, maka ia diharuskan untuk membayar selisih biaya untuk peningkatan akomodasi layanan tersebut. ${ }^{3,4}$

Peserta BPJS Kesehatan akan memperoleh pelayanan kesehatan dilakukan secara berjenjang sesuai dengan kebutuhan medis pasien, mulai dari FKTP sampai dengan FKRTL dimana hal ini telah diatur dalam Peraturan Menteri Kesehatan Republik Indonesia (Permenkes R.I) No. 71 Tahun 2013. Fasilitas Kesehatan pada FKTP meliputi puskesmas, praktik dokter, praktik dokter gigi, klinik pratama dan Rumah Sakit Kelas D Pratama. FKTP yang bekerjasama dengan BPJS Kesehatan diharapkan dapat memberikan pelayanan kesehatan dasar dalam bentuk upaya kesehatan preventif, promotif dan juga surveilans. ${ }^{4,5,6}$

Peserta BPJS Kesehatan memiliki harapan yang tinggi tentang kualitas pelayanan yang akan diperoleh. Namun, dengan adanya aturan tentang kenaikan iuran BPJS Kesehatan yang tertuang dalam Peraturan Presiden Nomor 75 Tahun 2019 baru-baru ini memengaruhi terjadinya sejumlah 800 ribu peserta BPJS Kesehatan yang turun kelas usai pemerintah berniat menaikkan iuran pada awal tahun 2020 ini. Peserta yang turun kelas ini adalah yang terdaftar sebagai Peserta Bukan Penerima Upah (PBPU) atau mandiri. ${ }^{7,8}$ Walaupun menimbulkan berbagai polemik, kenaikan iuran ini dilakukan dengan tujuan untuk meningkatkan kepuasan peserta BPJS Kesehatan.

Tingkat kepuasan peserta terhadap pelayanan kesehatan di FKTP telah dievaluasi melalui pelaksanaan program JKN. Berdasarkan data secara nasional, tingkat kepuasan peserta BPJS Kesehatan terhadap pelayanan kesehatan di FKTP pada tahun 2017 masih di bawah target. Hasil survei rata-rata tingkat kepuasan peserta BPJS Kesehatan terhadap pelayanan kesehatan di FKTP wilayah kerja Malang Raya (Kota Malang, Kabupaten Malang dan Kota Batu) pada tahun 2017 sebesar $(79,5 \%)$ masih berada di bawah target $(81 \%){ }^{9}$

Melalui dewan jaminan sosial nasional bekerjasama dengan tim kementerian dari berbagai bidang, dan pelaksana badan penyelenggara telah menetapkan target kepuasan peserta BPJS Kesehatan. Sebagai salah satu dari 8 (delapan) sasaran pokok peta jalan jaminan kesehatan nasional tahun 2012-2019, target kepuasan peserta menentukan bahwa minimal $85 \%$ peserta menyatakan puas baik dalam pelayanan di BPJS Kesehatan maupun dalam 
pelayanan di fasilitas kesehatan yang bermitra dengan BPJS Kesehatan. ${ }^{8}$ Kepuasan peserta BPJS Kesehatan saat mendapatkan pelayanan kesehatan di FKTP akan memberikan pengaruh yang kuat terhadap loyalitas peserta dan kualitas pelayanan kesehatan pada umumnya.

Kepuasan merupakan salah satu indikator utama yang menentukan standar suatu fasilitas kesehatan. Kepuasan pasien dapat ditingkatkan dengan melakukan optimalisasi pengelolaan sistem pelayanan kesehatan. Mengetahui harapan dan pendapat pasien tentang pelayanan yang diperoleh merupakan langkah penting untuk mengetahui kualitas pelayanan kesehatan yang diberikan. Kepuasan pasien terhadap pelayanan kesehatan di FKTP tertentu akan berdampak pada pemanfaatan ulang terhadap pelayanan kesehatan tersebut.

Di Kota Malang, tingkat kepesertaan JKNKIS telah mencapai $75 \%$ dengan kepesertaan di tiga kecamatan yang telah mencapai > 90\%. Agar dapat meningkatkan kepuasan pasien, pelayanan kesehatan dapat melakukan standar pelayanan kesehatan secara lebih holistik dan komprehensif. Melalui penelitian ini diharapkan bahwa peserta BPJS Kesehatan lebih memahami tentang masalah kesehatan yang dirasakannya secara biologis, psikis, sosial dan spiritual sehingga mereka akan memperoleh pelayanan kesehatan yang lebih optimal. Adanya penurunan kepuasan peserta BPJS Kesehatan terhadap pelayanan di FKTP dan keterbatasan penelitian sebelumnya tentang kepuasan peserta BPJS Kesehatan, maka penelitian ini bertujuan untuk mengetahui gambaran karakteristik dan kepuasan peserta BPJS Kesehatan dalam pemanfaatan pelayanan kesehatan di FKTP Kota Malang.

\section{METODOLOGI}

Studi ini merupakan penelitian deskriptif yang menggunakan pendekatan survei observasi untuk memperoleh generalisasi terhadap suatu gambaran umum dari sebuah fenomena. Gambaran karakteristik peserta BPJS di FKTP Kota Malang ini kemudian dijadikan dasar untuk penelitian selanjutnya yang lebih mendalam.
Penelitian ini melibatkan sejumlah 49 peserta BPJS yang ada di FKTP Kota Malang yaitu pada FKTP Klinik Pratama dan FKTP Puskesmas. Penentuan sampel dengan systematic random sampling dengan melakukan observasi data terkait jumlah kunjungan pasien terbanyak di FKTP Klinik Pratama dan FKTP puskesmas. Pengambilan sampel dilakukan pada waktu jumlah kunjungan pasien terbanyak berdasarkan hasil observasi data. Variabel penelitian ini adalah kepuasan peserta BPJS Kesehatan. Sumber data diperoleh melalui peserta BPJS yang memeriksakan kondisi kesehatannya di FKTP Klinik Pratama dan FKTP Puskesmas. Instrumen yang digunakana adalah kuesioner yang terdiri dari data demografi dan kepuasan peserta BPJS. Data dianalisis secara deskriptif dengan menggunakan SPSS 20.0.

\section{HASIL DAN PEMBAHASAN}

Sejumlah 49 peserta BPJS Kesehatan dilakukan pengambilan data terkait karakteristik peserta dan kepuasan peserta dalam pemanfaatan pelayanan kesehatan di FKTP Kota Malang. Dapat dilihat pada Tabel 1 bahwa rerata usia peserta BPJS Kesehatan adalah 39-41 tahun. Hal ini juga dijelaskan oleh Centers for Disease Control and Prevention tentang perubahan kenaikan tekanan darah yang cukup signifikan pada suku Afrika Amerika yang berusia 35-64 tahun. Pada rentang usia 30-40 tahun, berbagai jenis penyakit kronis juga mungkin tidak memiliki gejala yang berarti ataupun tidak terdiagnosa karena berbagai hambatan sosial dan ekonomi. ${ }^{10} \mathrm{Hal}$ ini menjadi penting bahwa peserta BPJS memperoleh manfaat pelayanan surveilans, preventif dan promotif untuk mencegah terjadinya keparahan penyakit dan menimbulkan beban finansial masyarakat yang lebih jauh lagi. BPJS Kesehatan merupakan salah satu strategi untuk menurunkan beban finansial masyarakat miskin sehingga mereka mampu memperoleh akses pelayanan kesehatan yang lebih baik. ${ }^{11}$ 
Tabel 1. Distribusi Usia Peserta BPJS

\begin{tabular}{lcc}
\hline Nilai & $\begin{array}{c}\text { FKTP Klinik } \\
\text { Pratama }\end{array}$ & $\begin{array}{c}\text { FKTP } \\
\text { Puskesmas }\end{array}$ \\
\hline $\begin{array}{l}\text { Rerata } \\
\text { Mean })\end{array}$ & 39,38 & 40,96 \\
$\begin{array}{l}\text { Standar } \\
\text { Deviasi }\end{array}$ & 14,70 & 14,32 \\
$\begin{array}{l}\text { Minimal } \\
\text { Maksim }\end{array}$ & 18,00 & 19,00 \\
al & 80,00 & 72,00 \\
\hline
\end{tabular}

Tabel 2. Karakteristik Peserta BPJS di FKTP Klinik Pratama

\begin{tabular}{llcc}
\hline \multirow{2}{*}{ Indikator } & \multicolumn{1}{c}{$\begin{array}{c}\text { Kategori } \\
\text { (Modus) }\end{array}$} & \multicolumn{2}{c}{ FKTP Klinik } \\
& \multicolumn{1}{c}{ Pratama } \\
Jenis & Laki-laki & 9 & 27,3 \\
kelamin & Perempuan & 24 & 72,7 \\
& $\leq 30$ tahun & 9 & 27,3 \\
Usia & 31-45 tahun & 21 & 63,6 \\
& $\geq 45$ tahun & 3 & 9,1 \\
Pindah & Tidak pernah & 33 & 100 \\
FKTP & Pernah & 0 & 0 \\
\multirow{3}{*}{ Status } & PBI & 0 & 0 \\
kepesertaan & PPU & 25 & 75 \\
& PBPU & 8 & 25 \\
\hline
\end{tabular}

Berdasarkan hasil analisa Tabel 2, peserta BPJS Kesehatan di FKTP Klinik Pratama yang terbanyak adalah berjenis kelamin perempuan $(72,7 \%)$, berusia antara 31-45 tahun $(63,6 \%)$, seluruh peserta tidak pernah pindah FKTP dan sebagian besar (75\%) status kepesertaan BPJS Kesehatan adalah PPU. Dalam Peraturan Presiden Nomor 82 tentang Jaminan Kesehatan, PPU terdiri dari pejabat negara, pimpinan dan anggota Dewan Perwakilan Rakyat Daerah, pegawai negeri sipil, prajurit, anggota polri, kepala desa dan perangkat desa, pegawai swasta dan pekerja yang menerima gaji ataupun upah. ${ }^{3}$ Pada studi ini diperoleh hasil bahwa peserta PPU lebih banyak memeriksakan kesehatannya di FKTP Klinik Pratama, hal ini dimungkinkan terjadi karena FKTP Klinik Pratama memberikan pelayanan yang sesuai dengan kebutuhan pasien saat ini. Hasil penelitian ini juga didukung oleh studi sebelumnya dimana
FKTP Klinik Pratama senantiasa berupaya meningkatkan pelayanan kesehatan melalui berbagai cara. Sebuah studi terdahulu menjelaskan tentang pengembangan pelayanan klinik pratama berbasis aplikasi Customer Relationship Management (CRM) melalui website yang ditujukan untuk meningkatkan pelayanan pada pasien yang semula masih menggunakan proses secara manual. Hasil penelitian tersebut menunjukkan terjadinya peningkatan hubungan interpersonal antara pasien dengan FKTP Klinik Pratama melalui komunikasi yang berbasis database. ${ }^{12}$

Tabel 3. Karakteristik Peserta BPJS di FKTP Puskesmas

\begin{tabular}{|c|c|c|c|}
\hline \multirow{2}{*}{ Indikator } & \multirow{2}{*}{$\begin{array}{l}\text { Kategori } \\
\text { (Modus) }\end{array}$} & \multicolumn{2}{|c|}{$\begin{array}{c}\text { FKTP } \\
\text { Puskesmas }\end{array}$} \\
\hline & & $\mathrm{n}$ & $\%$ \\
\hline \multirow{3}{*}{$\begin{array}{l}\text { Jenis } \\
\text { kelamin }\end{array}$} & Laki-laki & 0 & 0 \\
\hline & Perempuan & 16 & 100 \\
\hline & $\leq 30$ tahun & 3 & 18,8 \\
\hline \multirow[t]{2}{*}{ Usia } & $31-45$ tahun & 6 & 37,5 \\
\hline & $\geq 45$ tahun & 7 & 43,7 \\
\hline \multirow{3}{*}{$\begin{array}{l}\text { Pindah } \\
\text { FKTP }\end{array}$} & Tidak pernah & 16 & 100 \\
\hline & Pernah & 0 & 0 \\
\hline & PBI & 16 & 100 \\
\hline \multirow{2}{*}{$\begin{array}{l}\text { Status } \\
\text { kepesertaan }\end{array}$} & PPU & 0 & 0 \\
\hline & PBPU & 0 & 0 \\
\hline
\end{tabular}

Pada Tabel 3 dapat dideskripsikan karakteristik peserta BPJS di FKTP Puskesmas dimana seluruh pesertanya adalah perempuan. Sedangkan usia terbanyak yang datang ke FKTP Puskesmas berusia lebih dari 45 tahun $(43,7 \%)$. Sama halnya dengan FKTP Klinik Pratama, peserta BPJS di FKTP Puskesmas juga tidak pernah pindah FKTP. Lain halnya dengan FKTP Klinik Pratama yang lebih banyak didominasi oleh peserta PPU; seluruh peserta BPJS di FKTP Puskesmas memiliki status kepesertaan PBI. Peserta PBI merupakan peserta penerima bantuan iur yang ditetapkan sebelumnya oleh menteri yang berkaitan dengan urusan kepemerintahan di bidang sosial. $^{3}$ 
Tingkat pengetahuan, sikap dan perilaku petugas kesehatan sangat berpengaruh terhadap pemilihan FKTP. ${ }^{13}$ Peserta BPJS yang memilih FKTP Puskesmas pada umumnya cenderung lebih memanfaatkan pelayanan kesehatan terdekat karena tidak adanya pilihan pelayanan kesehatan yang lain. Peserta PBI juga lebih memilih memanfaatkan pelayanan gratis yang sudah diberikan oleh Pemerintah. ${ }^{14}$ Terdapat beberapa faktor yang memengaruhi tercapainya akses pelayanan kesehatan di FKTP Puskesmas, yaitu manajemen puskesmas, sistim JKN, adanya pustu/polindes/poskesdes, FKRTL, tenaga kesehatan, sarana infratruktur, aparatur desa dan kebijakan pelayanan kesehatan yang tersedia. ${ }^{15,16}$

Tabel 4. Kepuasan Peserta BPJS Kesehatan di FKTP Klinik Pratama dan Puskesmas

\begin{tabular}{|c|c|c|c|c|c|}
\hline \multirow[t]{2}{*}{ Indikator } & \multirow[t]{2}{*}{ Kategori } & \multicolumn{2}{|c|}{$\begin{array}{c}\text { FKTP } \\
\text { Klinik } \\
\text { Pratama }\end{array}$} & \multicolumn{2}{|c|}{$\begin{array}{c}\text { FKTP } \\
\text { Puskesmas }\end{array}$} \\
\hline & & $\mathrm{n}$ & $\%$ & $\mathrm{n}$ & $\%$ \\
\hline \multirow{4}{*}{$\begin{array}{l}\text { Kepuasan } \\
\text { pada aspek } \\
\text { biologis }\end{array}$} & $\begin{array}{l}\text { Sangat tidak } \\
\text { puas }\end{array}$ & 0 & 0 & 0 & 0 \\
\hline & Tidak puas & 0 & 0 & 0 & 0 \\
\hline & Puas & 5 & 15,15 & 7 & 43,75 \\
\hline & Sangat puas & 28 & 84,85 & 9 & 56,25 \\
\hline \multirow{4}{*}{$\begin{array}{l}\text { Kepuasan } \\
\text { pada aspek } \\
\text { psikis }\end{array}$} & $\begin{array}{l}\text { Sangat tidak } \\
\text { puas }\end{array}$ & 0 & 0 & 0 & 0 \\
\hline & Tidak puas & 0 & 0 & 0 & 0 \\
\hline & Puas & 7 & 21,21 & 6 & 37,50 \\
\hline & Sangat puas & 26 & 78,79 & 10 & 62,50 \\
\hline \multirow{4}{*}{$\begin{array}{l}\text { Kepuasan } \\
\text { pada aspek } \\
\text { sosial }\end{array}$} & $\begin{array}{l}\text { Sangat tidak } \\
\text { puas }\end{array}$ & 0 & 0 & 0 & 0 \\
\hline & Tidak puas & 0 & 0 & 0 & 0 \\
\hline & Puas & 13 & 39,39 & 8 & 50,00 \\
\hline & Sangat puas & 20 & 60,61 & 8 & 50,00 \\
\hline
\end{tabular}

Kepuasan peserta BPJS Kesehatan terhadap pelayanan di FKTP merupakan indikator utama yang menentukan kualitas pelayanan kesehatan. Kepuasan pasien mempengaruhi hasil evaluasi klinis, retensi pasien, dan efisiensi perawatan. ${ }^{17}$ Kepuasan peserta dalam penelitian ini meliputi kepuasan tentang pelayanan kesehatan pada aspek biologis, aspek psikis dan aspek sosial saat memanfaatkan pelayanan kesehatan di FKTP. Tabel 4 menjelaskan tentang tingkat kepuasan peserta BPJS di FKTP Klinik Pratama yang lebih banyak didominasi oleh aspek biologis $(84,85 \%)$, sedangkan kepuasan pada aspek psikis lebih banyak dirasakan oleh peserta BPJS di FKTP Puskesmas. Kebutuhan pelayanan pada aspek psikis dapat ditingkatkan melalui komunikasi yang efektif, sikap hangat, dan empati antara petugas medis pada pasien. Pada akhirnya hal ini dapat meningkatkan kepuasan bagi kedua belah pihak. ${ }^{4}$ Pada saat ini FKTP Puskesmas sudah meningkatkan standar pelayanan kesehatan minimal dan menjadi garda terdepan dalam memenuhi kebutuhan kesehatan pasien.

Pada umumnya pasien yang datang ke FKTP menginginkan adanya kepastian diagnosa terkait keluhan yang dialaminya dimana sebagian besar adalah keluhan secara biologis. Sebagian besar pasien menyatakan kekecewaannya jika tidak mendapatkan kepastian terkait dengan keluhan yang dialaminya dan pengobatan yang sesuai dengan yang diharapkan. Kepuasan pasien juga ditentukan dari seberapa jauh tindakan intervensi yang diberikan pada pasien. Bahkan, banyak pasien yang mengatakan lebih puas jika ia diresepkan obat sesuai dengan keluhan fisik yang dirasakannya. ${ }^{17,18,19}$ Hal ini menandakan bahwa sebagian besar masyarakat masih memiliki keyakinan yang kuat bahwa sakit itu harus diobati dan lebih bersifat kuratif daripada preventif. Petugas medis di FKTP juga dapat meningkatkan kepuasan peserta BPJS dengan membina hubungan interpersonal yang lebih erat. Pendekatan komunikasi efektif juga dilakukan sebagai upaya promotif dan preventif agar keyakinan masyarakat tentang konsep sehat-sakit menjadi lebih jelas.

Adanya gambaran tentang tingkat kepuasan di kedua FKTP menunjukkan bahwa belum optimalnya petugas medis dalam memberikan pelayanan kesehatan secara holistik dan komprehensif sesuai dengan kebutuhan dasar pasien. Penatalaksanaan penyakit harus dituntaskan secara holistik dengan mengidentifikasi berbagai aspek keluhan pasien dan lebih peka pada aspek biopsikososial, budaya dan spiritual pasien. Petugas medis tidak hanya bertanggung jawab untuk meningkatkan status kesehatan pasien yang datang ke FKTP, namun juga memiliki tanggung jawab yang lebih 
luas lagi pada keluarga, masyarakat dan juga lingkungan disekitarnya sebagai upaya untuk menyelesaikan permasalahan kesehatan secara holistif dan komprehensif. ${ }^{4}$

\section{SIMPULAN DAN SARAN}

Kesimpulan penelitian ini menunjukkan bahwa peserta PBI lebih banyak memeriksakan kesehatan di FKTP Puskesmas dan kepuasan pada aspek biologis lebih dirasakan pada pelayanan kesehatan yang diperoleh di FKTP Klinik Pratama. Kepuasan peserta BPJS Kesehatan di FKTP Klinik Pratama dan FKTP Puskesmas perlu ditingkatkan melalui pendekatan holistik komprehensif dengan upaya promotif, preventif, kuratif dan rehabilitatif. Penelitian selanjutnya diharapkan mampu mengembangkan pelatihan holistik dan komprehensif pada kedua jenis FKTP, baik FKTP Klinik Pratama maupun FKTP Puskesmas.

\section{UCAPAN TERIMA KASIH}

Penulis mengucapkan terima kasih yang sebesar-besarnya pada Fakultas Kedokteran Universitas Muhammadiyah Malang atas dukungannya selama penulisan artikel ini.

\section{REFERENSI}

1. Setyawan FEB. Sistem Pembiayaan Kesehatan. Jurnal Berkala Ilmiah Kedokteran dan Kesehatan [serial on the Internet]. 2018 [cited 2020 Maret 20]; 2 (4): 57-70. Available from: https://jurnal.unimus.ac.id/index.php/APKKM/ar ticle/view/3336/3164.

2. Badan Penyelenggara Jaminan Sosial. UndangUndang Republik Indonesia No.24 Tahun 2011 [regulation on the internet]. November 2011 [cited 2020 Maret 28]. Available from: https://djsn.go.id/storage/app/uploads/public/58c/ 24d/0e4/58c24d0e4ed39439756046.pdf.

3. Jaminan Kesehatan. Peraturan Presiden Republik Indonesia Nomor 82 Tahun 2018 [regulation on the internet]. September 2018 [cited 2020 Maret 28]. Available from: https://sipuu.setkab.go.id/PUUdoc/175595/Perpr es\%20Nomor\%2082\%20Tahun\%202018\%20ten tang\%20Jaminan\%20Kesehatan.pdf

4. Setyawan FEB. Pendekatan Pelayanan Kesehatan Dokter Keluarga (Pendekatan Holistik
Komprehensif). Sidoarjo: Zifatama Jawara; 2019.

5. CNN Indonesia. Iuran Naik, 800 Ribu Peserta BPJS Kesehatan Turun Kelas [serial on the internet]. Januari 2020 [cited 2020 Maret 28]. Available from: https://www.cnnindonesia.com/ekonomi/202001 20164938-78-467052/iuran-naik-800-ribupeserta-bpjs-kesehatan-turun-kelas.

6. Pelayanan Kesehatan Pada Jaminan Kesehatan Nasional. Peraturan Menteri Kesehatan Republik Indonesia Nomor 71 Tahun 2013 [regulation on the internet]. Oktober 2019 [cited 2020 Maret 28]. Available from: http://www.depkes.go.id/resources/download/ge neral/PMK\%20No.\%2071\%20Th\%202013\%20tt g\%20Pelayanan\%20Kesehatan\%20Pada\%20JK N.pdf.

7. Perubahan Atas Peraturan Presiden Nomor 82 Tahun 2018 Tentang Jaminan Kesehatan. Peraturan Presiden Republik Indonesia Nomor 75 Tahun 2019 [regulation on the internet]. Oktober 2019 [cited 2020 Maret 28]. Available from: https://bpjskesehatan.go.id/bpjs/dmdocuments/d24f3714c05 0f7cab8f817c5f8717c84.pdf.

8. Badan Penyelanggara Jaminan Sosial Kesehatan Malang. Pelayanan Kesehatan Primer Tahun 2017. Unit Manajemen Pelayanan Kesehatan Primer Cabang Utama Malang BPJS Kesehatan. Malang: BPJS Kesehatan; 2017.

9. Mundiharno M, Thabrany H. Peta Jalan Menuju Jaminan Kesehatan Nasional 2012-2019. Jakarta: Dewan Jaminan Sosial Nasional; 2012.

10. Centers for Disease Control and Prevention. African American Health Creating equal opportunities for health. [serial on the Internet]. 2017 [cited 2020 Maret 20]. Available from:https://www.cdc.gov/vitalsigns/aahealth/in dex.html.

11. Supriyanto S, Setyawan FEB, Ernawaty E, Prayoga D. Kebijakan Kesehatan dan Analisis Kebijakan. Sidoarjo: Zifatama Jawara; 2020.

12. Utomo YB, Winarno WW, Amborowati A. Perancangan Customer Relationship Management Pada Klinik (Studi Kasus: Klinik Pratama Nusa Medika Meritjan). Multitek Indonesia [serial on the Internet]. 2016 [cited 2020 Maret 20]; 10 (1): 57-68. Available from: http://dx.doi.org/10.24269/mtkind.v10i1.239.

13. Ridwan R. Faktor Yang Berhubungan Dengan Pemilihan Fasilitas Kesehatan Tingkat Pertama Pada Peserta Non Penerima Bantuan Iuran di 
Wilayah Kerja Puskesmas Lima kaum I Kabupaten Tanah Datar Tahun 2016. Diploma thesis. Padang; Universitas Andalas, 2016.

14. Irawan B, Ainy A. Analisis Faktor-Faktor Yang Berhubungan Dengan Pemanfaatan Pelayanan Kesehatan Pada Peserta Jaminan Kesehatan Nasional Di Wilayah Kerja Puskesmas Payakabung, Kabupaten Ogan Ilir. Jurnal Ilmu Kesehatan Masyarakat [serial on the Internet]. 2018 [cited 2020 Maret 20]; 9 (3): 189-197. Available from: https://doi.org/10.26553/jikm.2018.9.3.189-197.

15. Kurniawan YT. Faktor-Faktor dan Pola Hubungannya yang Mempengaruhi Pemanfaatan Jaminan Kesehatan Nasional (JKN) oleh Keluarga Miskin. Jurnal Cakrawala [serial on the Internet]. 2017 [cited 2020 Maret 20]; 11 (1): 8393. Available from: http://cakrawalajournal.org/index.php/cakrawala/ article/view/7/7.

16. Rumengan DSS, Umboh JML, Kandou GD. Faktor-Faktor yang Berhubungan dengan Pemanfaatan Pelayanan Kesehatan Pada Peserta BPJS Kesehatan di Puskesmas Paniki Bawah Kecamatan Mapanget Kota Manado. JIKMU [serial on the Internet]. 2015 [cited 2020 Maret 20]; 5 (1): 88-100. Available from: https://ejournal.unsrat.ac.id/index.php/jikmu/arti cle/view/7180.

17. Stamboglis N, Jacobs R. Factors Associated with Patient Satisfaction of Community Mental Health Services: A Multilevel Approach. Community Ment Health $J$ [serial on the Internet]. 2020 [cited 2020 April 7]; 56: 50-64. Available from: https://doi.org/10.1007/s10597019-00449-x.

18. Rosendal M, Carlsen AH, Rask MT. Symptoms as the main problem: a cross- sectional study of patient experience in primary care. BMC Fam Pract [serial on the Internet]. 2016 [cited 2020 Maret 20]; 7: 29. Available from: https://doi.org/10.1186/s12875-016-0429-8.

19. Sanchez-Piedra CA, Prado-Galbarro FJ, GarciaPerez S, Santamera AS. Factors associated with patient satisfaction with primary care in Europe: results from the EUprimecare project. Quality in Primary Care [serial on the Internet]. 2014 [cited 2020 April 7]; 22: 147-55. Available from: https://primarycare.imedpub.com/factorsassociated-with-patient-satisfaction-withprimary-care-in-europe-results-from-theeuprimecare-project.pdf. 